\title{
US health officials investigate sexually transmitted Zika virus infections
}

\author{
Michael McCarthy
}

Seattle

Health officials in the United States are investigating 14 reports of possible sexual transmission of the Zika virus, including several cases involving pregnant women, US Centers for Disease Control and Prevention (CDC) officials have confirmed.

In two of the cases, Zika virus was confirmed in women whose only known risk was sexual contact with an ill male partner who had recently travelled to an area with local Zika virus transmission. Tests on the male partners were still pending at the time of the announcement.

"In all events for which information is available, travellers were men and reported symptom onset was within two weeks before the non-travelling female partner's symptoms began," the CDC said.

In four of the cases preliminary IgM antibody testing was positive, but confirmatory testing was pending. For the eight remaining cases investigations were ongoing, the $\mathrm{CDC}$ said.

Although Zika virus is spread primarily by the bite of infected Aedes mosquitos, the new reports said that sexual transmission of the virus may be more common than previously thought. At this time there was no evidence that women could transmit Zika virus to their sexual partners, the CDC said.

The virus was first reported in the western hemisphere in 2014. Since then it has spread through much of the Americas and has now been reported to be circulating in 28 countries and territories in central and south America. Reports-primarily from Brazil-have linked Zika virus infections to a surge in fetal and newborn microcephaly, and neurological complications such as Guillain-Barré syndrome.

Although a link between the infection and microcephaly is suspected, the virus is being considered "guilty until proven innocent," by the World Health Organization. ${ }^{1}$ In response to the reports of microcephaly and other neurological complications, however, WHO declared the Zika outbreak in the Americas to be a public health emergency of international concern on 1 February. ${ }^{2}$

There have been no reports of local transmission through mosquito bites in the US. However, there have cases reported in the US Virgin Islands and American Samoa, both US territories.

CDC recommended that men with a pregnant partner who reside in or have travelled to an area of active Zika virus transmission should abstain from sexual activity or consistently use condoms during sex-including vaginal intercourse, anal intercourse, or fellatio-for the duration of the pregnancy. Men who were concerned about sexual transmission of Zika virus but whose partners were not pregnant should abstain from sexual activity or use condoms consistently during sex.

The CDC recommended that exposed persons with signs or symptoms consistent with Zika virus disease should be tested, and that testing should be offered to asymptomatic pregnant women with possible exposure to Zika virus. The agency does not currently recommend testing of exposed but asymptomatic men for the purpose assessing the risk of sexual transmission.

For all The BMSs latest articles on the Zika epidemic go to bmj.co/zika.

Gulland A. Genetically modified mosquitos may be used in fight against Zika. BMJ 2016;352:i1086doi:10.1136/bmj.i1086.

2 Gulland A. Zika virus is a global public health emergency, declares WHO. BMJ 2016;35:i657doi:10.1136/bmj.i657

Published by the BMJ Publishing Group Limited. For permission to use (where not already granted under a licence) please go to http://group.bmj.com/group/rights-licensing/ permissions 